\title{
ASPECTOS DA ALIMENTAÇÃO DE GENIDENS GENIDENS (VALENCIENNES) (SILURIFORMES, ARIIDAE) NA BAÍA DE GUARATUBA, PARANÁ ${ }^{1}$
}

\author{
Paulo de Tarso da Cunha Chaves ${ }^{2}$ \\ Ana Lúcia Vendel ${ }^{3}$
}

\begin{abstract}
Features of the feeding of GENIDENS GeNidens (VAlenciennes) (Siluriformes, Ariddae) at the Guaratuba Bay, Parana. Seasonal variation of the food items of the "bagre-urutu", Genidens genidens is analysed based on monthly samples between September, 1993 and April, 1995 at the Guaratuba Bay, coast of Parana. The stomach contents of 105 fish is analysed by the Occurrence Frequency Method and 41 of these have also been analysed by the Volumetric Method. Matching both methods using the Preponderance Indices, a larger incidence of decapods is determined, followed by other crustaceans, molluscs, polychaets, fish, and plant material. The data show the existence of a strong seasonal variation in the diet.
\end{abstract}

KEYWORDS. Guaratuba Bay, Estuary, Ariidae, Seasonal Variation, Diet.

O bagre-urutu, Genidens genidens (Valenciennes, 1839), é um Ariidae muito comum na fauna de fundo da Baía de Guaratuba, Paraná. No litoral deste Estado, investigações já realizadas com a espécie incluem estudos sobre comportamento em laboratório (FANTA-FEOFILOFF et al. 1983), ocorrência na Baía de Paranaguá (CORRÊA 1987), e incubação de ovos e larvas pelos adultos em meses de verão (CHAVES 1994). A respeito de sua dieta alimentar são disponíveis dados da Lagoa dos Patos (Rio Grande do Sul), onde a espécie ingere principalmente detritos, crustáceos e poliquetas (ARAÚJO 1984) e do complexo estuarino lagunar de Cananéia (São Paulo), onde fazem parte de sua dieta crustáceos decápodes, anelídeos, zooplâncton, moluscos e peixes (MISHIMA \& TANJI 1982).

Este trabalho descreve a dieta da espécie na Baía de Guaratuba e sua provável variação sazonal. Tal investigação faz parte de um projeto maior, cujo objetivo central é descrever as relações existentes entre a Baía de Guaratuba e sua comunidade de peixes, visando dimensionar a importância recíproca entre as partes.

\section{MATERIAL E MÉTODOS}

Realizou-se uma análise sazonal do conteúdo estomacal de 105 exemplares de Genidens genidens, coletados entre setembro de 1993 e abril de 1995, na área de

1) Contribuição número 930 do Departamento de Zoologia, Universidade Federal do Paraná. Com auxílio do CNPq e FUNPAR.

2) Departamento de Zoologia, Universidade Federal do Paraná. Caixa Postal 19020, 81531-990 Curitiba, Paraná, Brasil. Bolsista do CNPq.

3) Bolsista Iniciação Científica (PIBIC/CNPq). 
manguezal da Baía de Guaratuba, litoral do Paraná (2552'S - 48³9'W, figura 1). As capturas ocorriam ao início da manhã, através de arrasto de fundo com portas, em profundidades que não excediam a 5 metros. Os exemplares foram transportados em caixa isotérmica com gelo desde o local de coleta até o laboratório, decorrendo cerca de 5 horas entre sua morte e a fixação dos estômagos (solução de formol a $10 \%)$. O número de exemplares estudados e sua distribuição de comprimento total por estação do ano, bem como os dados de temperatura e salinidade na região de coleta (médias entre superfície e fundo), estão indicados na tabela I. Os itens presentes no conteúdo foram analisados com auxílio de lupa e microscópio, sendo tratados, em todos os exemplares disponíveis, pelo método Freqüência de Ocorrência (FO - quantidade de estômagos que apresentavam o item em questão, em relação ao total de estômagos com conteúdo). Além disso, em 41 destes exemplares aqueles obtidos no último ano de coleta, os itens foram analisados também pelo método Volumétrico ( $\mathrm{V}$ - proporção de quadrículas ocupadas por item numa superfície plana quadriculada, em relação ao número total de quadrículas ocupadas pelo conteúdo). Ao final, os resultados procedentes deste grupo foram conjugados através do Índice de Preponderância (NATARAJAN \& JHINGRAN 1961 apud JURAS \& YAMAGUTI 1985), definido como IP=Vi.FOi / ( $\Sigma$ Vi.FOi). 100, onde "i" é cada um dos itens considerados. Para o inverno, tal Índice não foi calculado, visto não estarem disponíveis dados do Método Volumétrico (ausência de exemplares no último inverno do período).

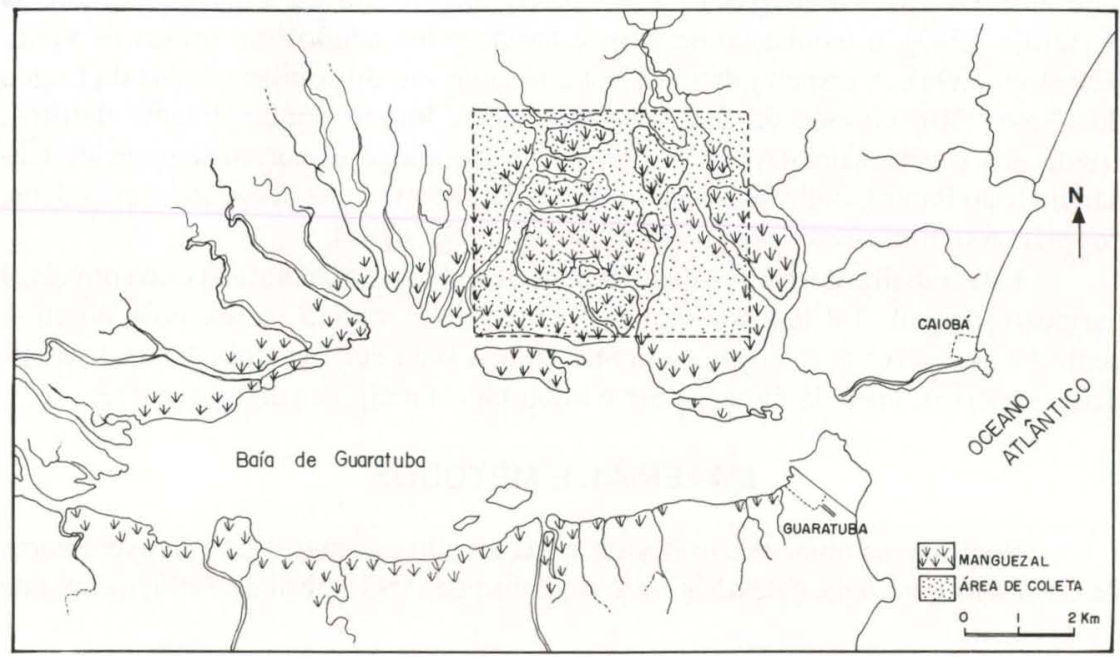

Fig. 1. Localização da área de estudo (retângulo pontilhado) dentro da Baía de Guaratuba, litoral do Paraná (2552'S -48⒊'W). 
Tabela I. Quantidade (n) e amplitude de comprimento total dos exemplares analisados, valores médios de salinidade, temperatura da água e temperatura atmosférica, segundo a estação do ano e local de coleta.

\begin{tabular}{lcccc}
\hline & Verão & Outono & Inverno & Primavera \\
\hline $\mathrm{n}$ & 31 & 15 & 18 & 41 \\
Menor exemplar $(\mathrm{mm})$ & 158 & 122 & 128 & 107 \\
Maior exemplar $(\mathrm{mm})$ & 280 & 278 & 357 & 212 \\
Salinidade média $(\mathrm{ppmil})$ & 20,6 & 31,8 & 35,2 & 24,6 \\
Temperatura d'água $\left({ }^{\circ} \mathrm{C}\right)$ & 20,6 & 25,4 & 18,1 & 21,0 \\
Temperatura da atmosfera $\left({ }^{\circ} \mathrm{C}\right)$ & 25,3 & 25,3 & 17,0 & 22,0 \\
\hline
\end{tabular}

\section{RESULTADOS}

Os registros de conteúdo estomacal segundo a estação serão apresentados com base principalmente no Índice de Preponderância. Todavia, algumas observações - sempre que julgadas oportunas - farão referência conjunta ou específica aos métodos Volumétrico ou Frequiência de Ocorrência. Todos os dados podem ser vistos na tabela II e a especificação dos itens alimentares na tabela III. A conjugação dos itens de acordo com ambos os métodos e segundo a estação do ano é mais claramente demonstrada na figura 2 .

Tabela II. Participação média de itens do conteúdo estomacal de Genidens genidens segundo a estação do ano, através dos métodos de Frequência de Ocorrência (FO) e Volumétrico (V) - ambos expressos em porcentagem, e através da conjugação (I.P.).

\begin{tabular}{|c|c|c|c|c|c|c|c|c|c|c|c|}
\hline \multirow{2}{*}{ Item } & \multicolumn{3}{|c|}{ Verăo } & \multicolumn{3}{|c|}{ Outono } & \multirow{2}{*}{$\frac{\text { Inverno }}{\mathrm{FO}}$} & \multicolumn{3}{|c|}{ Primavera } & \multirow{2}{*}{$\frac{\text { Média }}{\text { I.P }}$} \\
\hline & FO & V & I.P. & FO & v & I.P. & & FO & v & I.P. & \\
\hline$n$ & 31 & 17 & 17 & 15 & 6 & 6 & 18 & 41 & 18 & 18 & 41 \\
\hline Decápodes & 67,7 & 93,0 & 97,856 & 66,6 & 51,8 & 66,188 & 27,7 & 31,7 & 22,1 & 24,092 & 62,712 \\
\hline Diversos & 12,9 & 0,5 & 0,100 & 46,6 & 17,7 & 15,825 & 44,4 & 31,7 & 15,4 & 16,788 & 10,904 \\
\hline Material vegetal & 35,4 & 2,8 & 1,540 & 26,6 & 0,4 & 0,204 & 16,6 & 21.9 & 9,3 & 7,004 & 2,916 \\
\hline Peixes & 3,2 & 0,2 & 0,010 & 33,3 & 24,4 & 15,589 & 33,3 & 24,3 & 13,3 & 11,114 & 8,904 \\
\hline Poliquetas & 3,2 & 1,1 & 0,055 & 0,0 & 0,0 & 0,000 & 27,7 & 31,7 & 32,5 & 35,429 & 11,828 \\
\hline Moluscos & 22,5 & 0,8 & 0,280 & 26.6 & 2,9 & 1,480 & 0,0 & 0,0 & 0,0 & 0,000 & 0,587 \\
\hline Não identificado & 6,4 & 1,6 & 0,159 & 13,3 & 2,8 & 0,714 & 22,2 & 21,9 & 7,4 & 5,573 & 2,149 \\
\hline Total & - & 100 & 100 & - & 100 & 100 & - & - & 100 & 100 & 100 \\
\hline
\end{tabular}

Tabela III. Relação dos itens alimentares registrados no conteúdo estomacal de G. genidens, com a maior especificação alcançada.

\begin{tabular}{ll}
\hline \multicolumn{1}{c}{ Item } & \multicolumn{1}{c}{ Especificação } \\
\hline Crustáceos decápodes & $\begin{array}{l}\text { Brachyura, entre eles Portunus spinimanus Latreille, 1819 e } \\
\text { Callinectes danae Smith, 1869. Caridae }\end{array}$ \\
Crustáceos diversos & $\begin{array}{l}\text { Amphipoda (Gammaridea, Caprellidea), Copepoda, Isopoda } \\
\text { (Pseudosphaeroma jakobii Loyola e Silva, 1959) }\end{array}$ \\
Material vegetal & $\begin{array}{l}\text { Algas, vegetais superiores } \\
\text { Peixes }\end{array}$ \\
Poliquetas & Presença de escamas ciclóides \\
Moluscos & Nereidae, Glyceridae \\
\hline
\end{tabular}




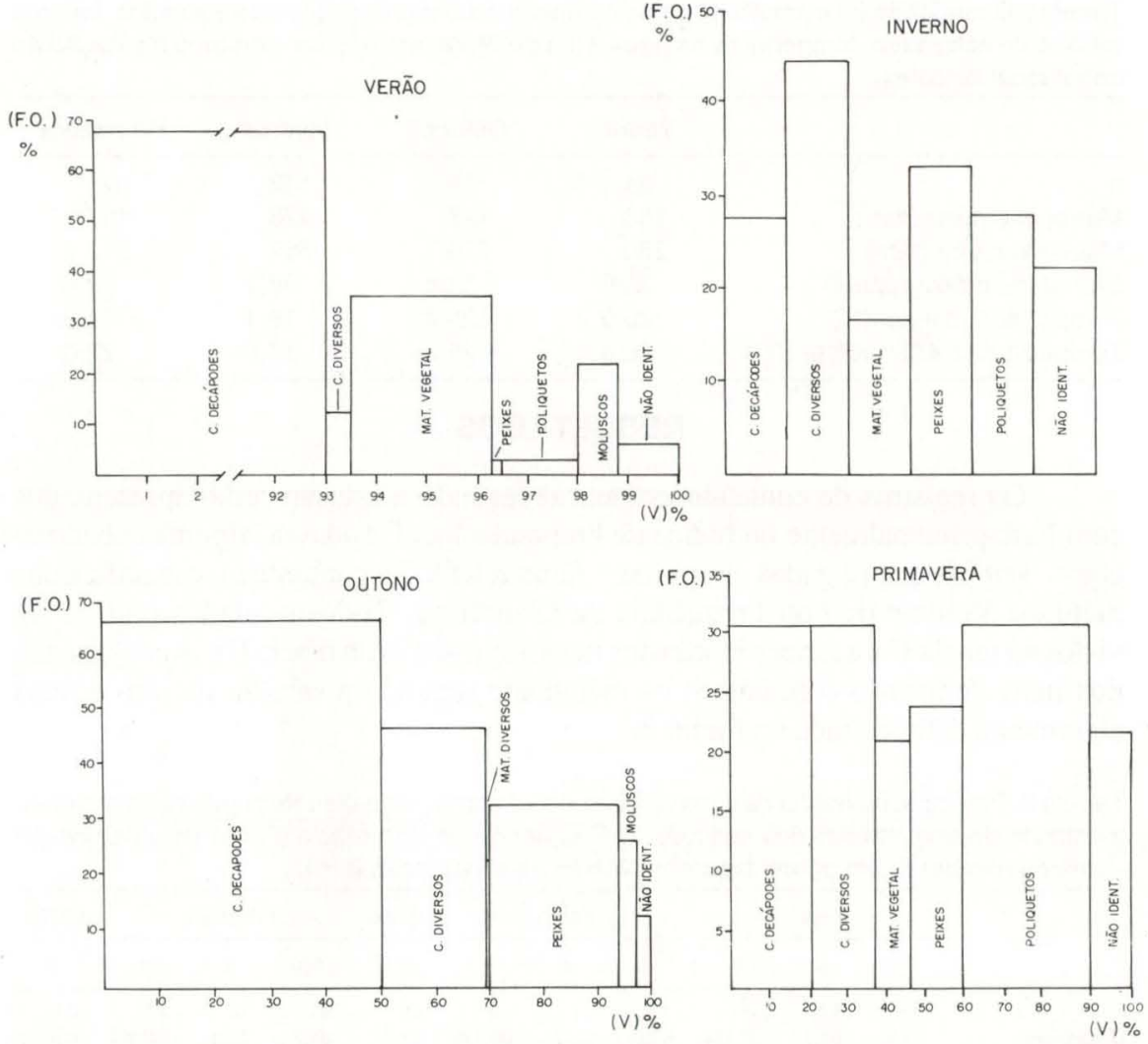

Fig. 2. Conjugação dos itens de acordo com o Método Freqüência de Ocorrência (F.O.) e Método Volumétrico (V.), segundo as porcentagens observadas em cada estação do ano. Com exceção do inverno, quando não foi feita análise pelo Método Volumétrico.

\section{VERÃO}

Crustáceos decápodes foi o item mais registrado nesta estação, seguido por material vegetal e moluscos. Outros crustáceos, poliquetas e peixes também participaram da dieta. Apenas 7\% do volume estomacal médio dos exemplares analisados não correspondia a crustáceos decápodes, evidenciando a significativa presença deste item no verão.

\section{OUTONO}

Novamente no outono crustáceos decápodes foi o item principal, desta vez seguido por crustáceos diversos e peixes. Embora em pequeno volume, moluscos e material vegetal estiveram presentes com uma freqüência que superou $25 \%$ dos exemplares analisados. Nesta estação, em média, cerca de metade do volume dos estômagos era ocupada por crustáceos decápodes. 


\section{INVERNO}

Os dados de inverno referem-se apenas ao método Freqüência de Ocorrência. Observaram-se maiores registros de crustáceos não-decápodes, seguidos por peixes, crustáceos decápodes e poliquetas. Material vegetal ocorreu em apenas 16,6\% dos exemplares analisados, e moluscos em nenhum deles.

\section{PrimaVera}

Poliquetas foi o item com maior registro, seguido por crustáceos decápodes e crustáceos diversos. Peixes e material vegetal também foram registrados, mas moluscos, novamente, não tiveram nenhum registro. Nesta estação constatou-se uma maior diversidade na dieta que nas anteriormente citadas: todos os cinco itens reconhecidos ocorreram em no mínimo $20 \%$ dos exemplares examinados, e em no máximo $32 \%$ deles. $\mathrm{O}$ volume por eles ocupado variou também dentro de limites relativamente próximos: entre 9,3 (material vegetal) e 32,5\% (poliquetas) do volume estomacal médio.

Em todas as estações, parte do conteúdo estomacal não pôde ser reconhecida. O volume médio deste material não-identificado atingiu no máximo $7,4 \%$ do conteúdo (primavera); quanto à Freqüência de Ocorrência, não foi registrado em mais que $22,2 \%$ dos exemplares analisados (inverno). Nematoda e grãos de areia também foram encontrados, mas não considerados como itens alimentares.

\section{DISCUSSÃO}

Os itens encontrados na dieta de Genidens genidens da Baía de Guaratuba apresentam algumas diferenças em relação àqueles registrados numa população de região mais ao norte [Cananéia -MISHIMA \& TANJI (1982)], e noutra de região mais ao sul [Lagoa dos Patos - ARAúJo (1984)]. Na primeira, foi encontrada uma forte participação de zooplâncton. Porém, este item estava restrito a classes de comprimento padrão inferiores a $10 \mathrm{~cm}$, enquanto em Guaratuba o menor indivíduo analisado possuia $10,7 \mathrm{~cm}$ de comprimento total. $\mathrm{Na}$ Lagoa dos Patos, um dos itens integrantes da dieta de $G$. genidens foram grãos de soja. Tal fato deveu-se à presença de um porto graneleiro na região, circunstância que não se verifica na Baía de Guaratuba. Entretanto, os itens "peixes" e "detritos" motivam incongruência parcial não facilmente explicável: ambos são registrados na Lagoa dos Patos, mas não em Cananéia. Quanto a Guaratuba, peixes efetivamente fazem parte da dieta de $G$. genidens, mas material detrítico não teve representatividade tão grande quanto a registrada mais ao sul. Evidentemente, podem existir fatores próprios a cada ambiente que expliquem tais diferenças.

Os itens crustáceos decápodes e poliquetos foram, tanto em Guaratuba como nas outras duas regiões acima referidas, elementos de grande representatividade na dieta da espécie. Todavia, deve-se ter em mente que a carapaça e os pereiópodes, por serem rígidos e em grande parte inorgânicos, naturalmente tendem a permanecer por mais tempo no estômago que outros itens, tendendo assim a superestimar a real ingestão de crustáceos, em especial decápodes, em relação a itens mais rapidamente digeríveis. Material vegetal, por sua vez, parece ter participação irregular na dieta 
de G. genidens, ocorrendo em volumes e freqüências bastante variáveis. De qualquer forma, tais registros indicam que a espécie não é exclusivamente carnívora, ainda que seja passível de discussão se a ingestão de tais vegetais é deliberada ou não, bem como sua importância como fonte de energia.

Constatou-se que a alimentação de $G$. genidens na Baía de Guaratuba é de alguma forma influenciada pelas condições ambientais, visto sua dieta apresentar diversas particularidades segundo a estação do ano. Uma dieta mais generalista, registrada na primavera, contrasta com a forte dominância de um item (crustáceos decápodes) no verão. Alguns itens não fazem parte da dieta em todas as estações: poliquetas estão ausentes no outono, enquanto moluscos no inverno e na primavera. Tais fatos provavelmente estejam associados à disponibilidade dos itens segundo a estação, entendendo-se como tal não apenas sua presença no local, mas também o quanto eles devem ser mais ou menos disputados com outros predadores. As fortes placas dentígeras de $G$. genidens atestam sua capacidade de aproveitamento de material rígido (carapaças, conchas, esqueletos); o estômago em fundo cego parece ser capaz de armazenar por longo tempo os itens ingeridos, enquanto se processa uma digestão que pode ser mais ou menos demorada; a fenda bucal pronunciada possibilita grande habilidade na ingestão de presas inteiras (peixes, por exemplo); os barbilhões mentonianos e maxilares, por sua vez, devem auxiliar no reconhecimento de itens do fundo, que por vezes parecem ser ingeridos acompanhados de sedimento. Tal pré-disposição anatômica pode ser responsável por seu hábito alimentar generalista e variável, talvez um fator determinante para que G. genidens seja uma espécie residente e abundante nesta região.

AGRADECIMENTOS. Aos pesquisadores Edinalva Oliveira, Dr. Arno Blankensteyn e Dr. Jayme de Loyola e Silva (Universidade Federal do Paraná), pela orientação prestada na identificação de crustáceos, poliquetas e isópodes respectivamente; ao Dr. Luiz Alberto Zavala Camin (Instituto de Pesca, São Paulo) e à Dra. Norma Segatti Hahn (Universidade Estadual de Maringá), pela leitura crítica da versão manuscrita. Ainda, a dois Revisores anônimos.

\section{REFERÊNCIAS BIBLIOGRÁFICAS}

ARAÚJO, F.G. 1984. Hábitos alimentares de três bagres marinhos (Ariidae) no estuário da Lagoa dos Patos (RS), Brasil. Atlântica 7: 47-63.

Chaves, P.T.C. 1994. A incubação de ovos e larvas em Genidens genidens (Valenciennes) (Siluriformes, Ariidae) da Baía de Guaratuba, Paraná, Brasil. Revta bras. Zool. 11 (4): 641-648.

CORRÊA, M.F.M. 1987. Ictiofauna da Baía de Paranaguá e Adjacências (Litoral do Estado do Paraná - Brasil). Levantamento e Produtividade. Dissertação de Mestrado, não publicada, Departamento de Zoologia, Universidade Federal do Paraná, Curitiba, 396p.

FANTA-FEOFILOFF, E.; N.S. TAKAHASHI \& A.T. BosCARDIM. 1983. Behavioural changes with temperature increase in the Ariidae Genidens genidens (Teleostei, Siluriformes). Arquivos de Biologia e Tecnologia, Curitiba, 26 (4): 535-544. JuRAs, A.A. \& N. YAMAGUTI. 1985. Food and feeding habits of king weakfish, 
Macrodon ancylodon (Bloch \& Schneider, 1801) caught in the southern coast of Brazil. Bolm Inst. oceanogr., São Paulo, 33 (2): 149-157.

Mishima, M. \& S. TANJ. 1982. Nicho alimentar de bagres marinhos (Teleostei, Ariidae) no complexo estuarino lagunar de Cananéia. B. Inst. Pesca, São Paulo, 9: $131-140$.

Recebido em 14.III.1996; aceito em 11.XI.1996. 